The Serials Librarian (The Haworth Press, Inc.) Vol. 34, No. 1/2, 1998, pp. 247-260.

Experimentation and Collaboration: Creating Serials for a New Millennium (ed: Charlene N.

Simser and Michael A. Somers) The Haworth Press, Inc., 1998, pp. 247-260.

(C) 1998 by the North American Serials Interest Group, Inc.

\title{
Understanding License Agreements for Electronic Products
}

\author{
Trisha L. Davis
}

John J. Reilly

Trisha L. Davis is Head, Continuation Acquisition Division, The Ohio State University Libraries. John J. Reilly is Associate Legal Counsel, The Ohio State University.

SUMMARY, Librarians regularly deal with license agreements when acquiring electronic products and services. As the librarian's role evolves from handling only the traditional serial subscription to managing these electronic services, a knowledge of contractual issues is mandatory. The actual license review process is complex and requires expertise and skills beyond the training and experience of most library staff. The presenters walk through the steps required to acquire and process a license agreement using a sample electronic product.

As serial librarians, our responsibility for dealing with license agreements for electronic products is unavoidable. None of us have been trained for this daunting task. As serial librarians, we are trained or experienced in selection. We can use much of our traditional training and many of our traditional tools to handle the collection development part of selection for electronic products. As serial librarians, we are trained or experienced in acquisitions. We can use much of our traditional training and our traditional connections with publishers, vendors, and agents to handle the basic acquisitions challenges for electronic products. As serial librarians, we are experienced, if not trained, in automation. We can use our expertise in using microcomputers, CD-ROMs, and the World Wide Web to deal with the technological issues involved in selecting and acquiring electronic products.

However, as serial librarians, we have never been trained to handle license agreements and many of us are not authorized to sign license agreements. The vast majority of us do not understand contract law. Most serials librarians simply wish these mysterious, complex, and frustrating contracts would disappear. Eventually they might, but not in the foreseeable future. Meanwhile, the actual license review and signature process continues to be complex. To manage it properly, a knowledge of contractual issues is mandatory. In reality, the handling of license agreements requires expertise and skill beyond the training and experience of most library staff.

This paper will discuss the more crucial factors needed to understand license agreements for electronic products and to establish library guidelines for reviewing, amending, and executing contracts. The focus is an understanding of three primary issues:

1. The license agreement as a form of legal contract and what it means to sign one.

2. The relationship and differences between the librarian's role and the legal counsel's role in reviewing, amending, and signing license agreements.

3. The basic elements of a typical license agreement for electronic products. 
This paper should not be construed as legal advice; its purpose is only to highlight issues common to license agreements. Any particular issues related to a license agreement should be discussed with legal counsel.

\section{UNDERSTANDING LICENSE AGREEMENTS AS A FORM OF LEGAL CONTRACT}

The producers of electronic products are in the publishing business. Like any business, the sales and distribution of electronic products are influenced by the legal environment. Unfortunately for both libraries and electronic publishers, the legal environment for defining and protecting on-line databases and electronic texts always has been complex and uncertain. The currently established copyright laws throughout the world simply do not address the unique issues related to works in electronic formats. In the meantime, advances in technology have made it easier to copy, transfer, or distribute information. Such capabilities threaten the commercial viability of any electronic product.

As a whole, the electronic publishing business has chosen two avenues of protection: (1) extremely complex and expensive pricing schemes to limit access; and (2) contract law as the best solution to protect intellectual property rights. By use of variant pricing models, the publisher can both restrict access and control distribution. Through contracts, the publisher can establish the basic business terms for use of the product. Thus publishers use the license agreement, as a form of contract, to restrict access, define use, and assure protection of their rights.

The first step in managing license agreements is to understand and remember that a contract is the embodiment of an agreement between parties. A license agreement, therefore, should include all the elements needed to satisfy both parties. The agreement as provided by the publisher will satisfy the publisher's needs; it has not been drafted to satisfy the library's or end user's needs. If a form of access, a use capability, or a payment option is not in the license agreement, it should be put in writing and added. A verbal promise regarding certain options or capabilities from a sales representative is not binding. The moment you sign a license agreement to the contrary, what the salesperson said becomes totally irrelevant. You may request and they can promise the sun, moon, and stars, but if it is not in the agreement, it cannot be enforced. A more realistic example is the need for remote access to an electronic product. Just because remote access is not strictly prohibited in the license agreement does not mean it is allowed. You should verify your rights to that capability by amending the license to include that option before allowing remote access. Make no assumptions. Every important concern should be spelled out in specific terms within the agreement and every detail should be complete.

\section{UNDERSTANDING WHAT IT MEANS TO SIGN A LICENSE AGREEMENT}

Everyone dealing with license agreements should understand clearly their role in the process as well as where/when they need to report. As a serials librarian handling license agreements for electronic products, you should determine both your responsibility and your authority to manage them. If you are asked to modify, negotiate, or sign a license agreement, you should immediately work through your reporting line to find out what the chain of command is and get that in writing! You must protect yourself by dealing with this issue pro-actively, not reactively.

The next step in managing license agreements is to determine exactly who within the institution has the authority to enter into contracts and exactly what type of contracts that person is trained to approve. For a private college or corporation library, it probably will be someone in 
the financial office. The source of assistance for public or school libraries will depend on the size of the system and will vary widely-from in-house expertise to external legal counsel paid by-thehour. At large public academic institutions, it is particularly difficult to identify the proper authority because of the size and complexity of administrative operations.

If a chain of command has not been established, campus counsel should be the first step. If campus counsel is not available, as on smaller campuses, there is probably a business officer or purchasing agent who has been charged with the responsibility. The responsibility for this function will vary from library to library. A staff person who handles contracts may be eminently qualified-perhaps a paralegal with many years of experience. You do not have to be a lawyer to review a license agreement, but you do have to understand the terms and be aware of the consequences.

To add to the confusion, in many states such as Ohio, there is no such concept as "apparent authority" in a public institution. For instance, if a university employee signs a license agreement and claims his signature is on behalf of The Ohio State University yet he does not have the proper authority to provide that signature, he has in fact assumed personal liability! The University would not be bound by this agreement. Needless to say, identification of the proper authority to sign license agreements is an extremely critical element within the process that cannot be ignored.

\section{UNDERSTANDING THE RELATIONSHIP BETWEEN THE LIBRARIAN AND LEGAL COUNSEL}

As a serials librarian, you cannot rely on legal counsel to understand and interpret the business or technical aspects of the license for you. Your legal counsel is going to have to rely on you to determine what you need technically and whether the product you are acquiring meets your library's requirements. No legal counsel can possibly know that, even if he or she is the institution's business officer. Your legal counsel generally will not superimpose his or her judgement on these issues but rather will rely on the judgement of the user when reviewing the license agreement.

The serials librarian must read the license agreement carefully. Until you can say you have read it and understood everything in it, and it meets all your needs, the license agreement should not be signed. Many libraries have a team of staff review the license agreement to assure the proper access, use capabilities, and user obligations are acceptable. Before the license is sent forward for review, the librarian responsible for managing the process should delete any unacceptable clauses, identify language to be revised, and prepare any additions to the contract. These comments and any questions about legal aspects are sent forward to legal counsel for review and signature. If significant changes are needed, the librarian and the attorney should work together to create language addenda to the license agreement and negotiate with the seller as needed. This is truly a team effort. Your legal counsel relies on you for the technical side of the business deal and you rely on your legal counsel to interpret any legal issues.

\section{UNDERSTANDING THE BASIC ELEMENTS OF A LICENSE AGREEMENT}

The final step in managing license agreements is to gain the expertise needed to understand the different elements of a contract. As mentioned earlier, most serials librarians will not be blessed with such knowledge upon reading their first license. The contractual language will vary from the almost casual and simple to the extremely formal and complex. Certain basic 
elements will be present in most license agreements, however, and an understanding of these contractual segments is key to simplifying the process.

\section{RECITALS}

Recitals are the formal statements at the beginning of license agreements that explain the reasons or purpose for which the contract is written. In a license agreement for electronic products, they normally identify the parties to the agreement and their intent to contract. Sometimes, they also serve to state the general purpose of the agreement. For the librarian, this is where you need to know exactly who is your contracting party and who is your authority. For instance, in a license agreement for The Ohio State University Libraries (OSU Libraries), the authorized contracting party is The Ohio State University on behalf of its Libraries.

\section{DEFINITIONS}

Nothing is as important to license negotiations as mutually understood definitions. A well-written license agreement often includes definitions that serve to eliminate confusion or false assumptions about terms used in the contract. If the license agreement does not contain a definitions section, you must hunt through the contract to determine how a term is defined. This is a tedious task, and use of key terms is easily overlooked.

Once you find the contractual definitions, most are "boilerplate," that is, the definitions are written to cover the widest number of possibilities. If you cannot find a definition for an important term, you should define it yourself and add it to the contract. If the license agreement does not provide adequate definitions, create your own and append them to the contract. The more effort you put into re-defining, clarifying, or adding definitions to the license, the more clear and concise the agreement will be. Just think of the serious problems misdefining terms such as "authorized user" or "site" could create. A specific definitions section of a license is quite desirable. If a license agreement that you are handling does not have a separate definitions section, feel free to create one and append it to the agreement.

\section{LICENSE GRANT}

The license grant is the heart of the agreement. This section should specify your rights and should outline exactly what the library and end user can and cannot do in terms of using the product. It has to be complete, it has to be specific, and it has to detail exactly what it is you expect to receive from the agreement. The license grant should outline three elements: (1) what you can do-your use capabilities; (2) what you cannot do-restrictions on use; and (3) what you must do-your obligations. If it does not do that clearly, then you need to modify it so that it does.

For instance, the license grant should tell you whether or, not you can reproduce search results, whether you have any rights to save data electronically, and whether you have to maintain a legend with the copyright on every printout. You need to pay attention to all these details because you are licensing the use of the product only. The product itself is not yours. You are paying only for access to it, which seems like buying it, but it is not actually your property. This is a lease, not a purchase.

The license grant for lease of an electronic product may be compared to the lease of a car. You sign a lease that states you can use the car for $\mathrm{X}, \mathrm{Y}$, and $\mathrm{Z}$. But, if you use it for W, you lose the license. Your contract may state that you may use the leased car for personal transportation and for business purposes. However, you may not have the right to hitch a trailer to the vehicle or to sublease it to a third party. If you do, your lease may be terminated and the car repossessed. 
An important reminder: with electronic products, if you use the product for an unauthorized purpose or allow unauthorized users, you may lose the license to the product. You also may violate copyright laws or the proprietary rights of the copyright holder.

\section{PROPRIETARY RIGHTS}

Most license agreements will include some notification of rights relating to copyright or trademarks. A typical example is the inclusion of a copyright notice when a user signs on to the database. Many times the agreements will require a notice-more frequently in the form of a clickon screen text-that the use of the database is governed by the subscription agreement between the user and the online vendor. Another example is the inclusion of an ownership or copyright statement at the bottom of each printed page. These requirements are included primarily to enforce restrictions on use. If there is no obligation for the library to police the system in any manner and if there is no obligation to report violations and take appropriate action, then the restrictions have little or no practical effect. If there are user obligations, these sections should be carefully read and understood.

A very important element related to proprietary rights is often missing in license agreements for electronic databases on CD-ROM. The library needs to be assured that the company providing the product will defend the library if the product provided is in violation of another's copyright. The license agreement should insure that the company will both hold you harmless and indemnify you if there is a copyright violation claimed against you. For example, you license a CD-ROM collection of short stories and the CD-ROM publisher states that they own all the rights or licenses to use the product. Later, one of your users informs you that he, not the vendor, owns the rights to one of the stories. He informs you that he is going to sue you because you have violated his copyright by letting patrons download his story! You need to make sure you clearly are protected from responsibility in this situation. Therefore, you should not agree to only a "hold harmless clause," which states that "we will not blame you if something happens." You also should insist on an indemnification clause that states "we will not blame you and if somebody sues you, we will take up your defense and we will pay for it." This clause will add additional protection should an inadvertent violation take place because of a copyright violation by the vendor.

In the grant of license, the publisher has stated your rights, your obligations, and your restrictions regarding lease of the product. If for any reason you do not understand the terms you are asked to agree to, then you should not sign the contract or license that product. You must be careful not to make promises that the library or the end user cannot or is likely not to keep. The library has any number of users out there and no one can make promises about what these users will and will not do. If Joe Copyright Abuser comes into the library with every intention of violating the copyright, you cannot make a promise on his behalf that he will abide by these terms. In signing a license, you can only say that the library will agree to these terms and will make a reasonable effort to notify users of the rights, restrictions, and obligations.

One final issue concerning proprietary rights is to beware of licenses limiting use of the product with other related products. In marketing the product, your sales representative responds to your question by stating that this Product A will work well with Product $\mathrm{X}$, which you already have installed on your network. Unbeknownst to you, however, Company A and Company X have no relationship and using these products together is a copyright violation. You must read the license carefully to verify that you have the right to use the product in this manner. Many licenses cite that Product A may not be used in combination with any other product 
manufactured by another corporation. You should also re-read the license for Product X and look for similar limitations.

To avoid a violation or copyright or proprietary rights and to assure that products may be used together, it is best to specify this particular use in writing and as a part of the signed license agreement. Even if Company $X$ states that they will indemnify you for use of this product in conjunction with other products they recommend or install, this may not protect you from violation. To be safe, state explicitly which products you will use and how you intend to use them as an addendum to the license agreement.

Finally, if the agreement states that the publisher or vendor will pay damages on your behalf for a copyright violation, be careful how they phrase it. If the license reads "Pay damages, or only those costs awarded by a court" that means that is all they will pay. While this is helpful, it does not begin to cover all costs. If you have to litigate and the case is settled, the publisher is not obligated to pay settlement costs. If the case is resolved otherwise, they are not required to pay your attorney's fees. You must read the license agreement extremely closely to make sure the vendor will pay any fees and costs, including settlement costs, court costs, and attorneys' fees resulting from this violation.

\section{WARRANTIES}

A warranty is an assurance that the item being leased or purchased meets certain quality and performance standards. In working with license agreements for electronic products, it is readily evident that warranty issues are very similar from contract to contract. Most license agreements for electronic products will not provide a tremendous amount of warranty. In most cases, the only warranty you will receive is a standard "fix and repair" warranty for the physical medium on which the data or software is delivered. If the product does not work for some reason, the vendor will repair or replace it or refund your money within " $x$ " number of days. While this is not an unreasonable approach, there are several issues to consider. For instance, how long is the warranty period? If it is going to take you 60 days to get the product installed and run the tests and your warranty period is 60 days, you basically have no warranty. You need to insure that your warranty provision realistically covers your needs. Most vendors will not give you an unlimited warranty; it would be nice to have that, but they will never agree to that. You can try to bargain that out, but you seldom will get what you want.

Many licenses have unusual requirements for replacement of lost or stolen media, such as CDs or disks. You may have to report the loss within a limited time period or file a police report and provide a copy to the vendor. If you cannot meet these obligations, you must delete these clauses from the license or risk serious penalties, including loss of access to the product. Finally, read the license agreement carefully for replacement fees or costs. In order to restrict illegal "sharing" of electronic products, some vendors charge exorbitantly high replacement fees for damaged, lost, or stolen disks. It is reasonable to charge a nominal replacement and handling fee for lost, stolen, or damaged disks. But if a disk or CD fails of its own accord or is unreadable upon receipt, you should not have to pay additional costs for replacement.

With the advent of Internet services, a guarantee of access availability becomes an important issue parallel to functional warranty. Access is a tricky issue because there may, in fact, be 5 or 6 links between the online product and your user. Many license agreements will disclaim that they cannot provide access at all times and probably rightfully so. What you might be able to negotiate is that the vendor is not responsible for any failures in the system or inability to access unless the failure to access is solely its fault. For example, if a vendor's system crashes 
or is taken down, the vendor could be held responsible. If loss of access is due to problems on your local or statewide network or a network provider, the vendor is not at fault. You should have a clear understanding of all links in the access networks and insure that the vendor will warrant access for those links it controls and the data it provides.

In the provision of electronic data, whether on physical media such as CDs or online access, electronic publishers or vendors normally will state that they are not responsible for the data. This may seem like a ludicrous attitude, but the vast majority of license agreements will disclaim any responsibility for completeness, accuracy, currency, or quality of data provided. The vendor normally is just collecting data into a single source for distribution. This disclaimer is an attempt to avoid damage claims related to information which it did not originate. The vendor is trying to protect itself from claims and any damages related to use of the product.

Now, having said this, beware of one major exception. In some cases, the purchase or lease of an electronic product will require the vendor's employees to come onto your premises to perform installation, maintenance, or repair. In this case, you should consider adding language saying that while the vendor may not be responsible for most damages, it will be responsible for physical injuries or property damage it caused while on site. Most vendors will acknowledge responsibility-but only if their employees are grossly negligent or guilty of intentional misconduct. You should consult with your legal counsel on this issue.

\section{LIMITATION OF LIABILITY}

In order to protect themselves in case of a claim, vendors often will try to limit the damages to the amount paid for the license. Given this limitation, the library should consider the cost of the license and the likelihood of risk. If the vendor simply mails a CD-ROM that will be mounted on a local computer, then there is an extremely limited relationship between the parties. Most likely it is not worth getting into a major negotiation to alter or delete the limitation of liability clause. On the other hand, if the library is acquiring a $\$ 40,000$ piece of software and related equipment that the vendor will install and service, then the library may want to consider removing that limitation of liability clause. You should discuss this issue with your legal counsel to obtain further guidance on these risk analyses.

\section{UPDATES}

If the viability of the product requires a series of updates or upgrades, the library must insure this is specified in the license agreement. This assurance also applies to training materials, documentation, and user aids. Such items should also be part of the definitions section. If not, the library should clearly define exactly what constitutes an update, an upgrade, how many training manuals, and what type of documentation or user aids they expect to receive during the course of the contract. If pricing is a factor, add a phrase such as "to be provided at no additional cost."

\section{PAYMENT AND RENEWAL}

Many license agreements will state exactly how and when the invoice is to be paid and to where it must be sent. The library must be certain that these requirements conform to local system needs and local accounting functions. The vendor normally asks for payment within thirty days of invoice, but often the library's system and time frames will vary. To ask for sixty days from initial receipt is often unacceptable to vendors because they may be required to move receipt to the next fiscal quarter. A good alternative is to suggest payment within 30 days from receipt in the institution's accounts payable office, which should accommodate your local 
accounts payable department needs.

The terms for automatic renewal of a subscription or license agreement also vary widely. The most common cancellation or renewal period is normally within 30 days prior to the end of the subscription period. Some license agreements extend this period to 90 days prior to expiration. If this time frame does not match the library's renewal cycle, this should be changed as necessary or the library must take special steps to assure a timely decision.

\section{TERM AND TERMINATION}

The term of the contract equates to the subscription period, implying a period of time with some definite termination. Most license agreements include a stated term for the lease. Often the actual acquisition cycle may take months, especially if review and negotiation of the license agreement is complex. The librarian should monitor the process and, if needed, alter the term or contractual start date to assure the subscription period coincides with initial access or receipt of the product.

Termination of the license agreement is equivalent to cancellation of the subscription before the subscription period ends. Termination may be by mutual agreement or as a result of one party breaching the agreed-upon terms of the contract. In general, what this provision will say is: "If you breach this contract, we must send you a notice stating that you have breached, and that you will then have 30 days within which to correct that breach." If the library does not correct the breach to the vendor's satisfaction, then the vendor can terminate the contract. This clause should be mutual, however, so that either party may terminate the agreement if a breach remains uncured. Also, if the library terminates because of breach by the vendor, the library should receive a refund of the license fee prorated over the license term.

\section{ASSIGNMENT}

Assignment is the ability to assign a contract or transfer rights to a third party. In a license agreement, assignment rights should be mutual and assignments and/or transfers should never be done without notice to the other party. It is highly unusual for a library to change ownership, but it is not uncommon in the business world. As a party to the license agreement, it is quite reasonable for you to request notice that the contract is being transferred and have the opportunity to cancel the contract, if you are so inclined.

\section{WAIVER}

A waiver of rights is normally the intentional or voluntary relinquishment of such rights. In a license agreement, the waiver clause normally states that neither party waives their rights involuntarily. A real-world example best explains this legal concept. Let's say your teenage son borrows your car and goes out joyriding. In the initial terms of your agreement, a rather pointed discussion with your son, you specifically stated that joyriding was forbidden. But when he returns home on Thursday night, you are tired, so you do not make an issue of it. Again on Saturday night, your son borrows the car and does the same. But this time, you are more awake when he gets home. You remind him of your agreement and as a consequence of his behavior, you take the keys and rescind his use of the car. He argues that you did not enforce this restriction on Thursday night, so you cannot do it now. You remind him that regardless of your behavior on Thursday, you have the right to enforce it now and you are doing so. This is the purpose of the waiver clause: just because you did not choose to enforce the contract on one occasion, does not mean you cannot enforce it now. 


\section{GOVERNING LAW}

This clause defines which set of laws will have binding legal force over the license agreement. Governing law is usually not as significant an issue for private institutions but is significant for public institutions. If you cannot accept another state's governing law, you have two choices: you may change the language to state the law under which you are governed or delete the paragraph in its entirety. Most vendors will accept either. Each library must consult legal counsel to determine local policy.

\section{NOTICES}

Notices are simply official communications between authorized parties as named in the agreement. This clause describes how you will officially communicate. This does not mean that every time you need to talk to your sales or service representative you must do so in writing. It does mean that the letter notifying them that the search software is not working properly will be issued formally in writing. And, if you are exercising your rights under the breach, that letter should be sent certified.

\section{SEVERABILITY}

$A$ severability clause will state that if one section of the license agreement becomes invalid, the remaining sections are not affected by that ruling and remain valid. Returning to the parent and son example: the parent may have stated that the son may drive to school, church, soccer practice, and the grocery store but not to the movies, to McDonald's, or to the mall. In time, the other parent overrules the restriction from driving to McDonald's, believing that McDonald's is a constitutional right of every teenager. In this case, the rest of the rules are still in effect, they are not thrown out just because the McDonald's restriction was overruled.

\section{ENTIRE AGREEMENT}

The entire agreement clause simply states that the entire agreement between the parties is contained in the license agreement, including any addenda or attachments. Any previously written agreements, any documents that otherwise govern your relationship and any previous representations from the company or any of its employees are no longer valid. This is standard legal language and fully acceptable if the terms of the license agreement otherwise are agreeable. Remember, generally you must get written agreement from the vendor for any changes you make to the agreement before they are valid and enforceable.

\section{FORCE MAJEURE}

The force majeure clause stipulates conditions beyond the reasonable control of the vendor or information provider that excuse poor performance or non-delivery of product. Normally, such conditions include wars, strikes, and traditional acts of God such as earthquakes and floods. This is standard language and not unreasonable, just be certain that both parties are subject to the same limitations. Some agreements state that if anything happens beyond their control, for example, their network carrier goes down, then they are not responsible because you could not access it.

\section{UNDERSTANDING THE VALUE OF LEGAL ADVICE}

Before making any changes to a license agreement, evaluate the changes in light of their 
worth to negotiate as a business analysis. Remember, whatever changes are made to a license agreement, they must be agreed to in writing by the vendor or they will not be valid and enforceable. Above all else, if you have questions about any legal terms, talk to your legal counsel. 